\title{
The Dilemma and Outlet of the Revision in Chinese Basic Units Contingency Plan
}

\author{
Limin Xu \\ Jinan University, Guangzhou, China \\ Email:1506746027@qq.com
}

How to cite this paper: $\mathrm{Xu}, \mathrm{L} . \mathrm{M}$. (2017) The Dilemma and Outlet of the Revision in Chinese Basic Units Contingency Plan. $A d$ vances in Applied Sociology, 7, 165-171. https://doi.org/10.4236/aasoci.2017.74010

Received: March 8, 2017

Accepted: April 15, 2017

Published: April 18, 2017

Copyright (C) 2017 by author and Scientific Research Publishing Inc. This work is licensed under the Creative Commons Attribution International License (CC BY 4.0).

http://creativecommons.org/licenses/by/4.0/

\begin{abstract}
The contingency plan is the basis for dealing with emergencies. In order to strengthen the emergency management, improve risk management and crisis response capacity, Chinese grassroots units and departments have prepared basic contingency plans. In the actual operation process, however, many outstanding problems are found in the preparation and management of contingency plans, such as the validity, pertinence and operability of the plans, the interlink problems of the upper and lower plans, and the revision of the plans. By discussing the problems which present during compiling, drilling and revising contingency plans, analyzing the deep-seated reasons existing in the emergency management process, putting forward the suggestions and measures to improve and realize the effect of the contingency plan.
\end{abstract}

\section{Keywords}

Contingency Plan, Emergency Management, Grass-Roots

\section{Introduction}

After the 2003 SARA incident in China, the "contingency plan", as a sudden emergency management of the terminolog, began to arouse the public's attention. By the end of 2004, the "overall plan-special plan-department plan-enterprises and institutions plan" for the axis of the emergency plan system is made by the central government to the local governments at all levels of emergency contingency plans full coverage. Since then, the national emergency plan system has been initially established (Zhan \& Gu, 2007).

The contingency plan is a plan for pre-empting plans to reduce the accident losses and to ensure the rapid, orderly and efficient emergency operation of the major contingencies or disasters. The central government regards "horizontal to the edge, vertical in the end" as the guiding ideology to instruct the contingency 
plans preparing work. Each level of the contingency plans is different but close with each other. After 10 years of exploration and development, as well as constantly practice tests, many problems have become increasingly prominent in contingency plans, and the urgency is to seek a breakthrough to properly solve these problems. The grassroots contingency plans are the first-line action plan in the event of an emergency response. However, there are many problems in China's grassroot contingency plan, such as the risk management and emergency management loopholes caused by these problems, which need to be properly addressed.

\section{Current Situation of Grassroots Contingency Plan Management}

Contingency plans can be considered as the last line of defense security for grassroots enterprises and institutions due to the uncertainly of accidents. One of the core ideas of the function of emergency plan is to deal with the uncertainty, change the crisis management to normal management (Liu, 2015). Faced with the increasingly frequent accidents, grass-roots contingency plans play more and more important role; however, in practice, the problems of grass-roots contingency plans are gradually highlighted.

\subsection{Invalid Preparation}

The contingency plan is a normative document for preventing and coping with emergencies. There are many special and typical problems in the preparation of the current grassroots contingency plan, which mainly include the following aspects: Firstly, the preparation process is not perfect. The preparation of the grassroots contingency plan does not arise much attention. In most cases, the leader appoints a few people and issues a preparatory task for the preparation of the plan. One reason why preparation of the contingency plans at the grassroots level drawing little attention is lacking of money and resources support, so that the preparation of the program, accustomed to copy the higher government contingency plans or other local government plans, plans to homogenization of the situation which is prominent. Secondly, the system content is unrealistic. The problem of the preparation process leads to the fact that the content of the plan does not meet the realistic requirements (State Council Emergency Management Office, 2013). Therefore, it is mainly manifested that the contingency plan has the problems of low operability, low relevance and low practicability. Thirdly, the plan format is not uniform due to the fact that each department plan structure format is not uniform, and emergency leaders do not have enough time to learn the contingency plan on scene. The role of the plan is difficult to carry out, and the plan thus becomes invalid short file.

\subsection{Emergency Drills in Form}

The emergency drills are as important as the preparation of the plan. The main purpose of contingency plan is to apply it to practice, to effectively prevent and 
deal with emergencies, and to minimize the damage caused by emergencies, all of which require frequent education, training and emergency drills. At present, many grass-roots governments in the preparation of contingency plans are often satisfied with the number of contingency plans, but ignore the emergency plan for the necessary exercise; or some grass-roots do some practice, but the advertising effect is greater than the actual effect. It is surprising that some grass-roots governments develop contingency plans only to cater for higher inspection and evaluation, and the release of the contingency plan becomes the end of the plan management.

\subsection{Plan Update Untimely}

The reality is always changing; and contingency plans should also be updated with the changing environment and resources. In daily emergency management work, there is not enough emphasis on the revision of the plan. For example, after the completion of the emergency exercise, the questions summarized in the exercise did not reflect the actual contingency plan, or the staff changes led to changes in the leadership structure of the contingency plan, as well as changes in emergency resources and environmental risks, which led to a decrease in the applicability of the emergency plan, resulting in mismatch in contingency plans and reality conditions.

\section{Analysis on the Reasons behind the Failure of Emergency Plan}

In order to solve the problems above, we need to explore the reasons behind these problems in order to fundamentally solve the problems.

\subsection{Ideological Understanding to Be Improved}

It is often very hard to take precautions against the incident events. When it happens, a large number of people and properties will be damaged in the event. However, people always holding fluke mind that it is "a small probability event" and they would be lucky enough to avoid encountering incidents, so it is meaningless to prepare for emergency contingency plan. On one hand, the necessary risk awareness is deficient, people think that the accident is more accidental, ahead formulation of the plan is a waste of time. On the other hand, the contingency plan is a decoration facade tool, to cater with higher-level behavior, grassroots lack courage and innovation to reform it. The emergency preparedness work is in passive; then the empiricism believes that the emergency is treated with experience, and dealing with incidents depending on the plan is "according to the script, unrealistic". These understandings make emergency preparedness work a simple act to cope with errands. It is precisely because of the existence of these ideas which tie the grass-roots management personnel, lead to the sloppy of their assessment work of local risk and emergency support capacity. Emergency planning and management work is not the in heart; emergency exercise is in formalization; and plan revision work can not keep up with the preparation of 
contingency plans; all of which are typical cases.

\subsection{Team Building to Be Strengthened}

As the saying goes, "To do good work must first sharpen his tools", the preparation of standardized and effective contingency plans must have a professional talents team. But the current grass-roots emergency management work is facing the status that the whole emergency system always indeed show too much staffs but with less workers, so they struggle to deal with the work. At the same time, professional training work has not kept up, so far, grass-roots contingency planning training yet to be started, many emergency personnel do not know how to prepare, maintain and manage contingency plans.

In the real work, some grass-roots governments try to hire a professional team to be responsible for the preparation of emergency plans to make up for the dilemma of professional talents. However, in the fact that the experts are unacquainted to local status quo as they do not comprehensively understand the situation of natural environment and emergency resources, and the experts belong to the governmental supernumerary staffs, there will be some obstacles for them to get access to the internal date, so that the plan is unpractical.

\subsection{Preparation of Cooperation to Be Formed}

Most grass-roots units in the preparation of the plan require multiple departments to participate, but in the actual work, they always commissioned a separate department responsible for and are with no strict requirements for other relevant departments at the same time. However, it should be emphasized that the process of preparation contingency plans is often more important than the text of the plan itself. The contingency plan needs various departments coordinating quickly and efficiently to work well. Therefore, it is necessary to involve a number of departments in the development process. Tasks and responsibilities of departments should be confirmed unequivocally, but the implementation is very difficult as it involves vital interests among various departments, which against the single department responsibility system of emergency preparedness in this stage.

Besides, the preparedness of contingency plans is a very professional work, not only need in-depth research, but also need to listen to multi-party views. A high-quality plan requires departmental experts to co-operation with the masses of people. But the contingency plan can not immediately play a role as the preparation of the work is basically "individual combat", and just a certain department of one or two person to complete the preparation (Xiao \& Xu, 2016). The quality of the preparation of plans greatly reduced as the staffs' ability falling short of realistic demand.

\subsection{Security Mechanism to Be Sound}

The implementation of emergency plans and the existing investment are not suited; mainly for the lack of talent and funding security deficiencies. There are a 
large number of emergency management staffs who are lacking of professional knowledge in China's grassroots level, but emergency management work is quite professional and it needs to undergo professional training and a long period of accumulated experience. Grass-roots manager flows frequently; a person in the same post can not be particularly long, but emergency management work experience is indeed the most important. In the regard of funds, the most typical performance is that the plan clearly defines in the emergency protection resources, however, in practice, because of limited financial resources, it is difficult to invest a lot of money to ensure the realization due to the local economic constraints. Lacking of financial support is the main reason for the absence of plans' revision, publicity, training, exercise and assessment work of the contingency plans.

\section{Suggestions on Improving the Management of Contingency Plans}

According to the above analysis, there are some recommendations about the work of grassroots emergency contingency plans' managements:

\subsection{Increase Awareness of the Misalignment (Li, 2014)}

Highly understand the importance and urgency of contingency plan management, which should be included in the agenda of public administration of grassroots units. As most of the initial events occurred at the grassroots level, it is extremely important if grassroots can prevent effectively and carry out promptly as well as disposal early. In order to do grassroots emergency management more fruitfully, the primary basis of the work is to prepare good contingency plans to strengthen the grassroots emergency plan dynamic management. In some sense, major emergency decision is mainly made by the grassroots leader personally, and they command others to execute, that's why emergency management is also called "The Number Projects". The grassroots leaders should pay high attention and be aware of the importance and urgency of the plan management, including the plan management work into the grassroots units' agenda, in order to make grass-roots emergency management to do a solid work.

\subsection{Improve the Risk Assessment}

The risk assessment is mainly aimed at the characteristics of emergencies, identifying the degree of harm to the event, analyzing the possible or derivative consequences of events and secondary, assessing the extent of the harm of various consequences and putting forward the control and governance risks measures. At the same time, the region emergency resources which can be called at the first time should be investigated and implemented comprehensively, as well as the cooperative areas, which will be requested for assistance in time. The implementation of most feasible emergency rescue program is to prepare better in a shortest possible time after the incident. 


\subsection{Strengthen the Overall System of the Plan}

In the preparation process, it is important to emphasize participation of the multi-sectors and multi-levels, especially in the case of contingency plans involved in cross-region, where the involvement of departments is even more important than the textual interpretation contained in the plan itself.

\subsection{Implement Emergency Drill Solidly and Effectively}

It is unsuitable to establish and improve the contingency plans after an accident. Emergency drills mechanism is a good optimization way. Emergency drill has two main roles, one is to test the emergency plan and find the plan's loopholes, the second is to train staffs, to increase their familiarity of the plan (Zhan, 2011). To do emergency drill effectively, it's very important that the emergency departments should be trained to strengthen the implementation of the emergency plan familiarity, so that the emergency contingency plan can be truly implemented. At the same time, dynamic and multi-scene practicable exercise mode can increase the simulation and combat effectiveness of the exercise. The emergency drill should make contact with the revision of the plan, so they can form a dynamic plan revision and update management model.

\subsection{Give Full Play of the Advantages of Professionals (Liu, 2015)}

In the view of lacking appropriate professionals during the preparation of the grassroots contingency plan, which results in the actual situation that preparation of the plan is with low quality. The preparation unit should choose to hire a professional, responsible planning team for the preparation of contingency plans. It can not only make full use of the professional staffs but also ensure the normative and scientific of the contingency.

\section{Conclusion}

Emergency preparedness work is an important work related to national security, social harmony and stability. Especially in the current period of social transformation, all kinds of emergencies occur frequently. It has a great significance to effectively reduce the incidence of emergencies, casualties and property losses, and to build a harmonious society. Emergency contingency plan is a technical document which requires high legal, practical and practical, and involves many disciplines, which must be carefully and scientifically treated instead of slightest false as any opportunistic practices can bring unexpected serious consequences. Therefore, grass-roots units in the preparation of contingency plans must be in accordance with relevant national laws and regulations of the standards and requirements, and reported to the relevant departments for approval of the record, taking preventive measures. This study only analyzes and expounds the existing problems in the current contingency plan revision work, and comes up with the improvement suggestions. But how to evaluate the emergency contingency plan, this paper does not carry on too much research and it appeals the academic and 
theoretical circles pay more attention to do further discussion.

\section{References}

Li, H. S. (2014). The Emergency Plan of American Enterprises and Its Enlightenment to China. Journal of Safety Science and Technology, 11, 65-70.

Liu, S. R. (2015). Crack the Path of the Current Grassroots Contingency Plans. China Emergency Management, 1, 54-57.

State Council Emergency Management Office (2013). Investigation Report on the Construction of National Emergency Plan System. China Emergency Management, 3, 8-11.

Xiao, W. T., \& Xu, Q. L. (2016). Grassroots Government Emergency Plan Management: Predicament and Outlet. Theoretical Discussion, 1, 12-16.

Zhan, C. Y. (2011). Research on the Perfect Path of Emergency Preparedness Plan in Dynamic Situation. Administrative Law Research, 1, 51-56.

Zhan, C. Y., \& Gu, L. S. (2007). Turning to the Corner: The Logic of the Contingency Plan. China Administration Management, 5, 89-92.

\section{Submit or recommend next manuscript to SCIRP and we will provide best} service for you:

Accepting pre-submission inquiries through Email, Facebook, LinkedIn, Twitter, etc. A wide selection of journals (inclusive of 9 subjects, more than 200 journals) Providing 24-hour high-quality service

User-friendly online submission system

Fair and swift peer-review system

Efficient typesetting and proofreading procedure

Display of the result of downloads and visits, as well as the number of cited articles Maximum dissemination of your research work

Submit your manuscript at: http://papersubmission.scirp.org/

Or contact aasoci@scirp.org 